\title{
Identification of novel genes that regulate androgen receptor signaling and growth of androgen-deprived prostate cancer cells
}

\author{
Elina Levina ${ }^{1,2}$, Hao $\mathrm{Ji}^{1}$, Mengqiang Chen ${ }^{1}$, Mirza Baig ${ }^{5}$, David Oliver ${ }^{1}$, Patrice \\ Ohouo $^{5}$, Chang-uk Lim ${ }^{1}$, Garry Schools ${ }^{1}$, Steven Carmack ${ }^{3}$, Ye Ding ${ }^{3}$, Eugenia V. \\ Broude $^{1}$, Igor B. Roninson ${ }^{1}$, Ralph Buttyan ${ }^{4, *}$, Michael Shtutman ${ }^{1, *}$ \\ ${ }^{1}$ Department of Drug Discovery and Biomedical Sciences, South Carolina College of Pharmacy, University of South Carolina, \\ Columbia, SC, USA \\ ${ }^{2}$ Department of Biological Sciences, University of South Carolina, Columbia, SC, USA \\ ${ }^{3}$ Wadsworth Center, NY State Department of Health, Albany, NY, USA \\ ${ }^{4}$ The Vancouver Prostate Centre, Vancouver, BC, Canada \\ ${ }^{5}$ Cancer Center, Ordway Research Institute, Albany, NY, USA \\ *These authors have contributed equally to this work \\ Correspondence to: \\ Ralph Buttyan, e-mail: rbuttyan@prostatecentre.com \\ Michael Shtutman, e-mail: shtutmanm@sccp.sc.edu \\ Keywords: prostate cancer, androgen receptor, shRNA, IGSF8, tumor progression \\ Received: February 02, $2015 \quad$ Accepted: April 10, $2015 \quad$ Published: April 23, 2015
}

\section{ABSTRACT}

Prostate cancer progression to castration refractory disease is associated with anomalous transcriptional activity of the androgen receptor (AR) in an androgendepleted milieu. To identify novel gene products whose downregulation transactivates AR in prostate cancer cells, we performed a screen of enzymatically-generated shRNA lenti-libraries selecting for transduced LNCaP cells with elevated expression of a fluorescent reporter gene under the control of an AR-responsive promoter. The shRNAs present in selected populations were analyzed using high-throughput sequencing to identify target genes. Highly enriched gene targets were then validated with siRNAs against selected genes, testing first for increased expression of luciferase from an AR-responsive promoter and then for altered expression of endogenous androgenregulated genes in LNCaP cells. We identified 20 human genes whose silencing affected the expression of exogenous and endogenous androgen-responsive genes in prostate cancer cells grown in androgen-depleted medium. Knockdown of four of these genes upregulated the expression of endogenous AR targets and siRNAs targeting two of these genes (IGSF8 and RTN1) enabled androgen-independent proliferation of androgen-dependent cells. The effects of IGSF8 appear to be mediated through its interaction with a tetraspanin protein, CD9, previously implicated in prostate cancer progression. Remarkably, homozygous deletions of IGSF8 are found almost exclusively in prostate cancers but not in other cancer types. Our study shows that androgen independence can be achieved through the inhibition of specific genes and reveals a novel set of genes that regulate AR signaling in prostate cancers.

\section{INTRODUCTION}

Metastatic prostate cancer $(\mathrm{PCa})$ patients are treated with androgen deprivation therapies (ADT) to deplete systemic androgen levels and inhibit androgen binding to the androgen receptor (AR) protein in prostate cancer (PCa) cells [1]. ADT extends survival of patients with metastatic disease but most treated patients will eventually recur with castration refractory prostate cancer (CRPC) that continues to grow and metastasize. Although ADT maintains systemic castrate levels of androgen, studies of CRPC tissues and experimental models of CRPC support the notion that CRPC cells remain addicted to AR-driven signaling. This is reinforced by the clinical 
success of new anti-androgens such as enzalutamide that significantly increase survival of CRPC patients. Mechanistic explanations for AR hyperactivity in CRPC cells include: 1) increased AR expression (with or without concomitant AR gene amplification); 2) AR mutations that allow promiscuous activation by non-androgens; 3) expression of constitutively active truncated AR splice variants produced by alternate splicing [2]; 4) intratumoral steroidogenesis that generates a local tumor microenvironment enriched for testosterone/ dihydrotestosterone; 5) tumor cell overexpression of AR co-activators that could further sensitize ARs in CRPC to castrate level androgens or alternate steroids.

Here we considered the hypothesis that AR is inherently capable of functioning under ADT but is functionally suppressed by some other proteins. Reduced expression of such proteins, a new class of PCa-specific tumor suppressors, might facilitate progression to CRPC. To identify genes that may act in this fashion, we developed a shRNA lenti-library screening procedure to identify and characterize genes, the knockdown of which increases the androgen-independent (AI) activity of AR in PCa cells. We combined a reporter-based selection procedure in which shRNAs from transcriptome-scale, enzymaticallygenerated libraries activate an AR-responsive reporter in androgen-dependent (AD) PCa cells (LNCaP) under the conditions of androgen depletion. Our strategy involved three sequential validation steps following the initial screening. First, we tested siRNAs against gene targets that were enriched following initial selection for the ability to increase the expression of an AR-responsive reporter in androgen-depleted medium. siRNAs that were validated at this step were further tested for effects on the expression of a panel of endogenous AR-regulated genes in androgendeprived cells. Finally, siRNAs that passed this validation were tested for their ability to enable androgen-independent growth of the cells. Using this protocol, we have identified both known and novel effectors of androgen signaling in androgen-deprived PCa cells. We further demonstrated that some of these genes, when inhibited, permit AI growth of AD cells, demonstrating for the first time that increased AR signaling and AI growth can be achieved through the inhibition of specific genes. Based on published studies, two of the AR signaling modulators identified in our screening, IGSF8 and CD9, appear to interact with each other in $\mathrm{PCa}$ progression.

\section{RESULTS}

\section{shRNA library screening for activation of an AR-responsive promoter}

LNCaP cells were stably transduced with a recombinant lentiviral vector expressing red fluorescent protein (DsRed) under the control of a modified rat probasin gene promoter (pARR2PB) [3] (Figure 1A).
These cells were first sorted by FACS to enrich for cells with minimal DsRed fluorescence in androgendepleted medium. Afterwards, they were again sorted in the presence of R1881 to select for cells with high DsRed fluorescence. The final population contained cells with a maximum dynamic range of induction by an AR ligand (Figure 1B). These reporter cells (PrbDsRed-LNCaP) expressed constitutively high levels of DsRed when transduced with a lentivirus expressing C-terminal truncated (constitutively active) AR, but not after transduction with a control (insert-free) lentivirus (Figure 1C). Two human shRNA libraries were used for our screen. The first library was prepared from a normalized mixture of cDNA from breast cancer cells $(2.8$ million total clones) and was previously described [4]. The second shRNA library was derived from a normalized mixture of cDNAs from AD LNCaP cells and AI PC3 cells (1.5 million total clones, see Methods).

The selection protocol (Figure 1D) is described in detail in Methods. Briefly, Prb-DsRed-LNCaP cells were transduced with lentiviral shRNA libraries. DNA from $10 \%$ of transduced cells was extracted immediately after transduction and used as a reference control; the remainder were maintained for 10 days in androgen-depleted medium to minimize basal reporter expression. Then, librarytransduced Prb-DsRed-LNCaP cells were FACS-sorted for high DsRed expressers that constituted approximately $3 \%$ of the infected cells. Genomic DNA from the high DsRed population was extracted, integrated shRNAs were PCR-amplified and sequenced using 454 massive parallel sequencing. BLAST analysis of the results yielded $\sim 20$, 000 sequences per dataset with homology to Unigene clusters. We identified 2913 genes that were 4 fold or more enriched in the high DsRed cell populations (summarized in Supplementary Table S1). The sets of genes selected using breast- and prostate-cell-derived libraries were largely non-overlapping, mainly due to the relatively low sequencing depth of the samples. Using this list of enriched genes we performed a comprehensive automated PubMed search to extract all publications relevant to androgen signaling. This search identified 69 genes that include both co-activators and inhibitors of AR-dependent transcriptional activation (Supplementary Table S2).

\section{Secondary siRNA screening and the effects of screen-selected siRNAs on the expression of endogenous androgen-regulated genes}

The flow chart of our validation analysis is shown in Figure 2A. Based on the level of enrichment we selected 200 genes (Supplementary Tables S3 and S4) from the primary enriched target list for secondary validation with individual siRNAs (4 different siRNAs per gene). We excluded known androgen signaling regulators and focused on genes that were not previously implicated in androgen signaling. To limit cell line- or reporter-specific effects, we 
A

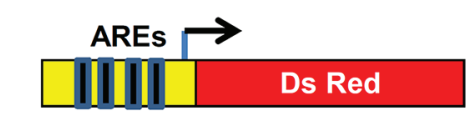

Rat Probasin

Promoter

B

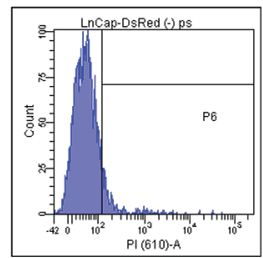

0 pM R1881

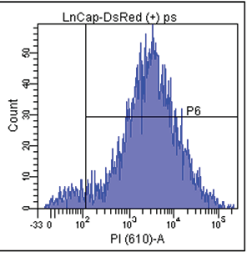

100 pM R1881
C
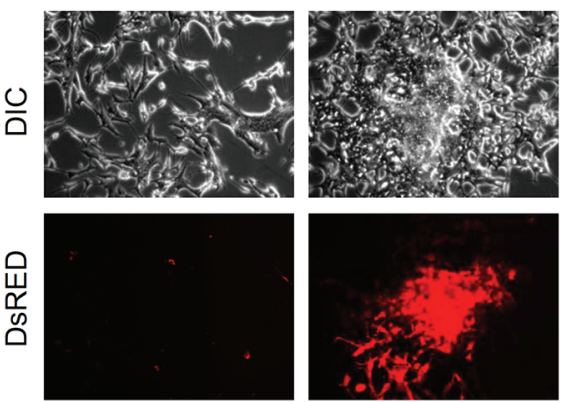

vector androgen receptor
D

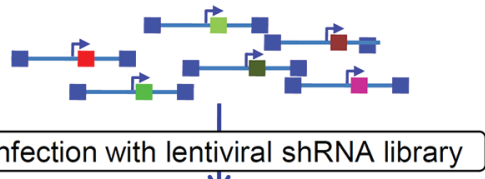

Infection with lentiviral shRNA library

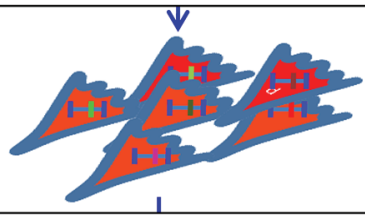

Cultivation in androgen-free medium

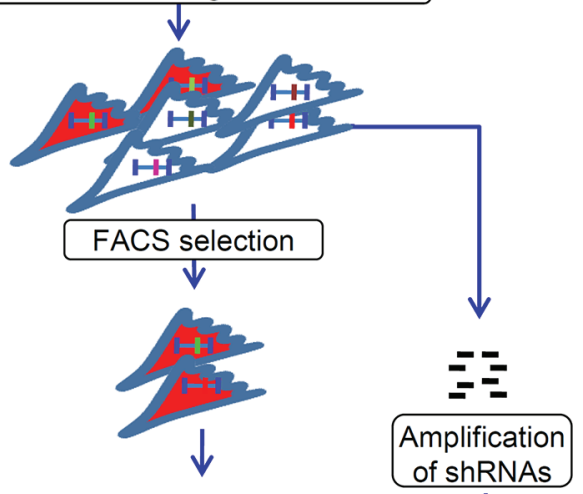

$\Xi \bar{E}$
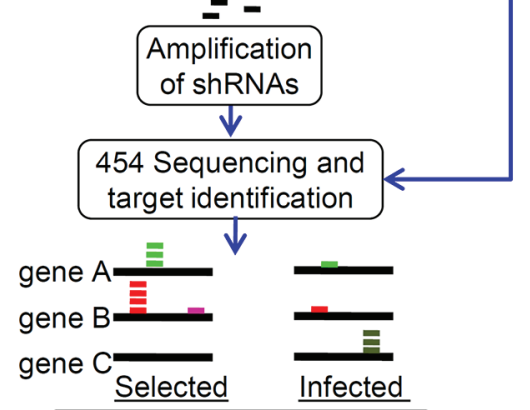

Identification of genes enriched in selected subset

Figure 1: High throughput screening for shRNAs stimulating AR activity in low androgen environment. A. AR-driven reporter construct containing Red fluorescent protein (DsRed II) under control of modified rat probasin promoter. B. FACS analysis of Prb-DsRed-LNCaP reporter cells. Cells were cultured in a hormone-free medium for 8 days (left). Cells were cultured in a hormone-free medium for 6 days followed by $48 \mathrm{~h}$ treatment with 100pm R881 (right). C. DsRed fluorescence is increased in Prb-DsRed-LNCaP reporter cells infected with AR-expressing (right) or a control lentiviral vector (left) and cultured for 8 days in hormone-free conditions. DIC (top) and fluorescence (bottom) microscopy, 20x magnification. D. Scheme of the selection and analysis of the shRNAs stimulating rat probasin promoter under hormone-free conditions.

tested siRNAs using a different reporter cell line, LNCaP cells with integrated probasin-luciferase reporter (PrbLuc-LNCaP, Figure 2B, 2C). Each siRNA was transfected individually into reporter cells that were then maintained in androgen-depleted medium and assayed for luciferase activity. The total amount of DNA in each sample was used to normalize the reporter activity. siRNAs were considered positive in this screen if at least two different siRNAs increased normalized luciferase expression by at least 1.5-fold over control siRNA-transfected cells.

Among the genes identified by our screen, nine encode different components of the 19S proteasome (highlighted in Figure 3A). It was previously shown that siRNA-mediated disruption of the 19S subunit inhibited AR signaling $[5,6]$. Since this was the most enriched class of genes in our selection, we analyzed the effects of the depletion of all the different $20 \mathrm{~S}$ and 19S proteasome subunits on the activity of the probasin promoter under androgen-free conditions. Whereas all siRNAs targeting 19S subunit genes dramatically increased luciferase reporter expression compared to non-targeting control siRNA, siRNAs targeting 20S subunit genes failed to achieve this effect (Figure 3C). Importantly, depletion of $19 \mathrm{~S}$ proteins resulted in a 14-fold elevation of luciferase 
B
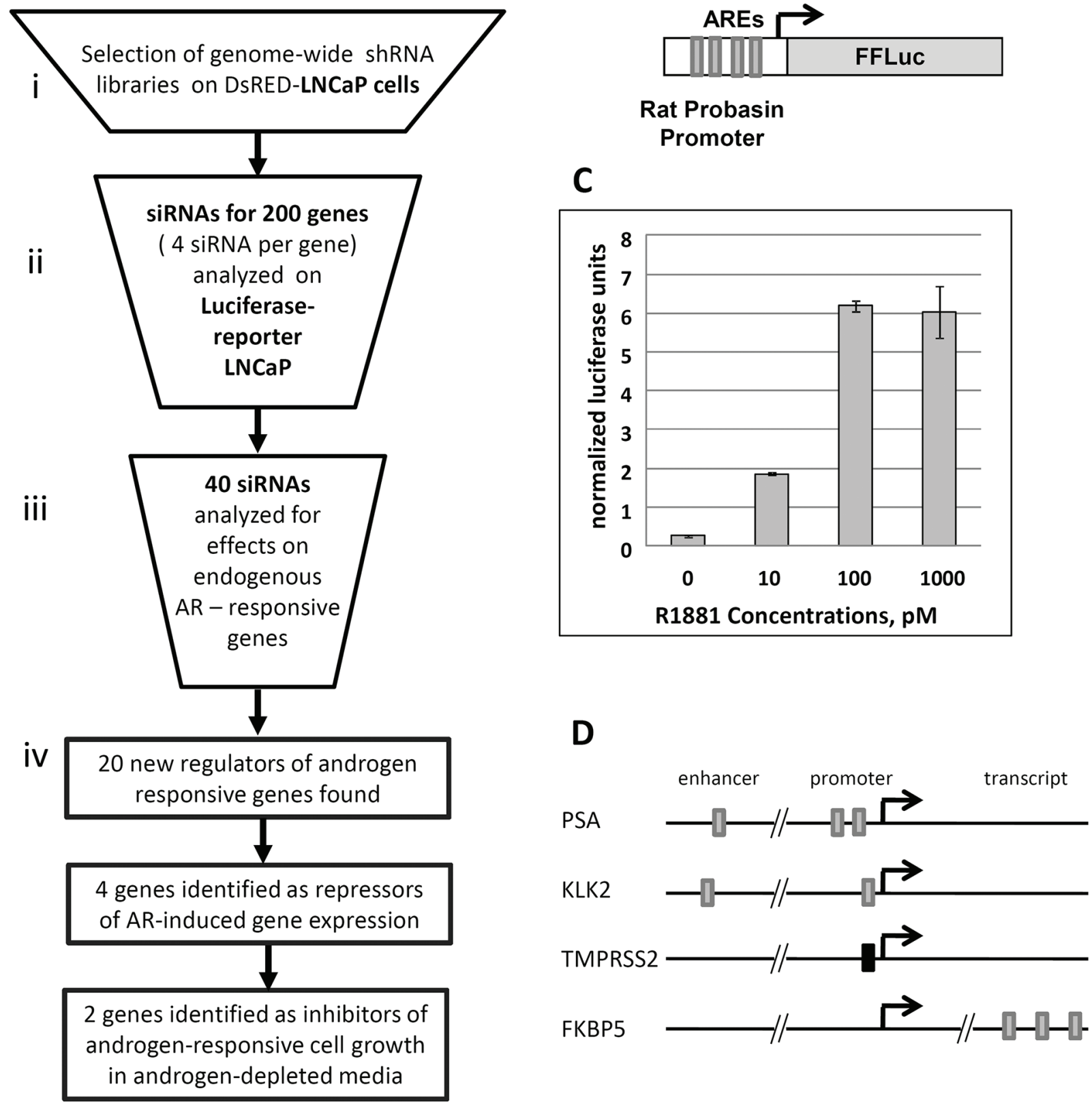

Figure 2: Validation of shRNA library selection procedure. A. Scheme of library screening and validation procedure. B. The AR-driven reporter construct containing Firefly Luciferase (FFLuc) under control of modified rat probasin promoter (validation, step 1) C. Androgen dose-dependent activity of the integrated luciferase reporter in Prb-Luc-LNCaP cells D. Localization of Androgen Responsive Elements (AREs) in the endogenous genes selected for QPCR based validation. Grey boxes represent canonical AREs, black box represents a non-canonical ARE.

mRNA, confirming the effect on the probasin promoter and arguing against potential stabilization of luciferase protein upon proteasome depletion (Figure 3B). Hence, our selection identified not only individual genes but also specific functionally related classes of genes that regulate the AR-dependent promoter function.

40 different siRNA sets with two or more siRNAs that upregulated luciferase expression in reporter cells were selected for the second validation step. Here, we determined the effects of the most active siRNAs for each gene on the expression of 4 endogenous ARresponsive genes with differing regulatory architectures (Figure 2D). We transfected the 40 most active siRNAs as well as a control siRNA into parental (non-reporter) LNCaP cells and, after 6 days androgen-depletion used qPCR to evaluate the expression levels of endogenous 


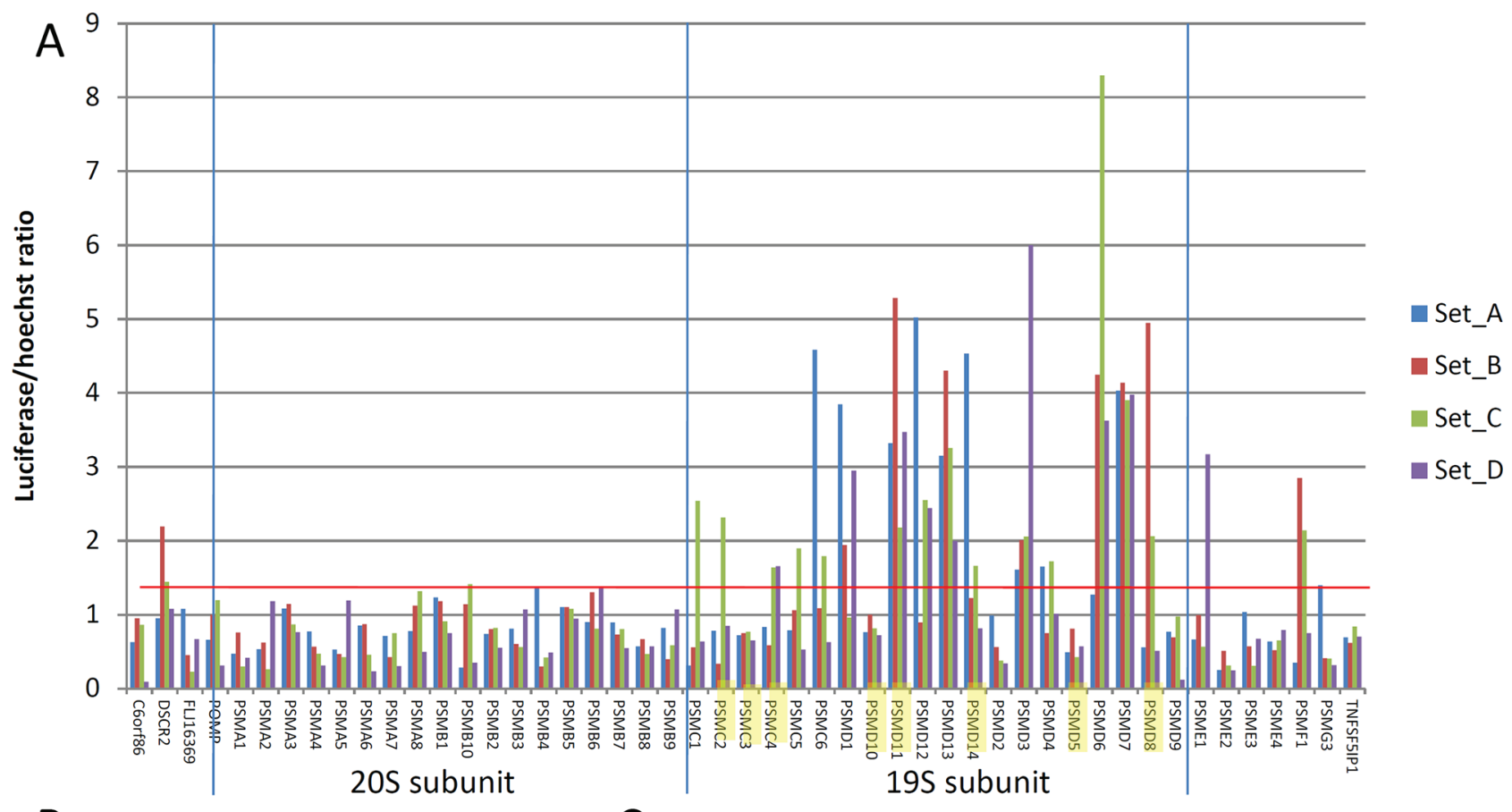

B

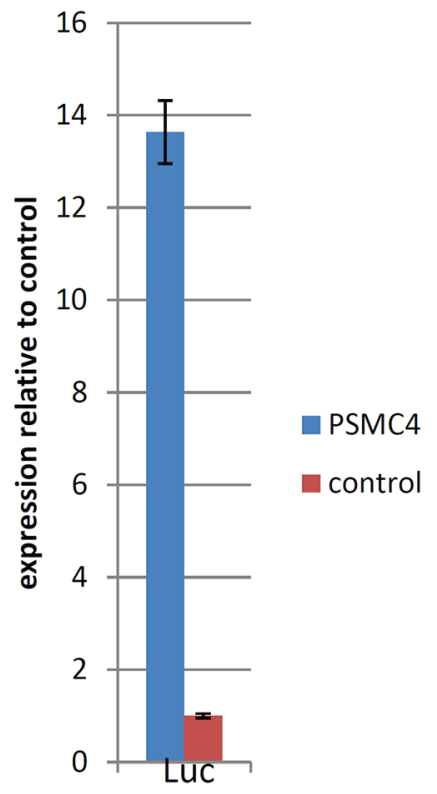

C

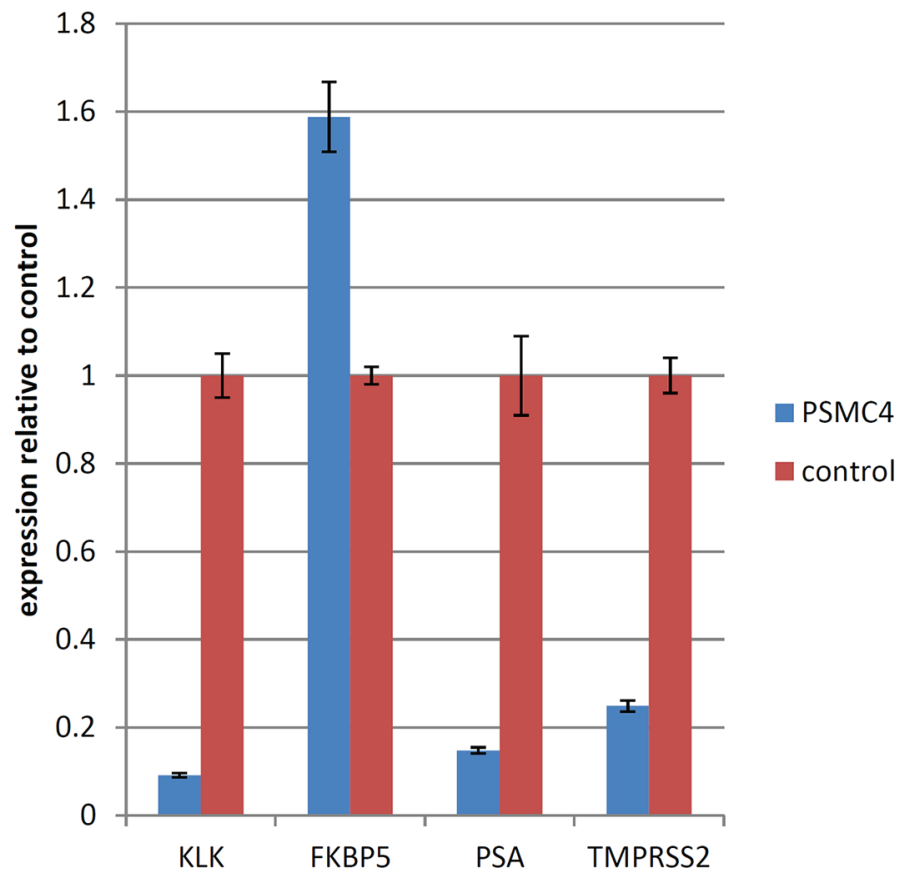

Figure 3: Effects of knockdown of proteasome complex subunits. A. Effects of siRNAs against the indicated proteasome components (4 siRNA per gene, sets A-D) on Prb-promoter activity measured by luciferase expression in Prb-Luc-LNCaP cells. Genes enriched in shRNA library selection are highlighted. Cells were transfected with siRNAs $(5 \mathrm{nM})$ in duplicates, cultured in hormone-free medium for 6 days, followed by measurement of luciferase activity. B-C. Reporter Prb-Luc-LNCaP cells were transfected with siRNA against 19S proteosomal component PSMC4 $(5 \mathrm{nM})$, cultured in hormone-free medium for 6 days, followed by QPCR analysis of expression of firefly luciferase B. or endogenous androgen responsive genes C. Results represent mean of 3 independent experiments $+/-$ SD.

AR targets such as KLK2, KLK3 (PSA), TMPRSS2 and FKBP5 (Figure 2A). siRNAs targeting 20 genes significantly affected the expression of endogenous androgen-regulated genes (Figure 4 and Supplementary Table S5) without any significant effect on the expression of AR mRNA (data not shown). Although the magnitude of the effects varied, depending on the specific endogenous gene and siRNA, we grouped the effective siRNAs into two classes: 1) those which mainly induced expression of endogenous androgen-regulated genes 
(4 siRNAs) and; 2) those which suppressed expression of endogenous genes (16 genes) (Figure 4A). Although siRNAs of both classes induced luciferase expression from the probasin promoter, all four genes in the first class induced the reporter by $>5$-fold, whereas only one of 16 genes in the second class had such a strong effect on the reporter (Figure 4A). To further confirm the target specificity of the selected siRNAs, we determined the effects of three independent siRNAs targeting PUF60, an RNA binding protein and negative regulator of c-MYC expression, on endogenous AR-regulated genes. All three siRNAs that reduced PUF60 expression (Supplementary Figure S2A) also significantly reduced the expression of KLK2, KLK3 and to a lesser degree, FKBP5, whereas only one siRNA significantly reduced the expression of TMPRSS2 in both androgen-free conditions and in the presence of $100 \mathrm{pM}$ R1881 (Supplementary Figure S2B, S2C).

Since the activity of co-regulators of steroid hormone receptors are often context-dependent [7-9], it is not surprising that the activity of genes that inhibit AR-dependent transactivation of the probasin promoter had different effects on different endogenous genes. Most of the active siRNAs affected mRNA levels of KLK2 and KLK3 (PSA) genes, promoters of which, similar to probasin, contain multiple canonical AREs [5, 11]. In contrast, FKBP5 and TMRSS2 genes, which contain either intronic or non-canonical AREs (Figure 2D) were considerably less affected (Figure 4A) [10, 11]. Therefore, the selection protocol that relies on ARE-driven reporter expression appears to target preferentially endogenous genes with canonical AREs upstream of the transcription initiation site.

\section{Effects of selected siRNAs on PCa cell growth in androgen deprived medium}

We assessed the effects of all four screen-selected siRNAs of the first class (targeting RTN1, IGSF8, C14orf147 (SPTSSA) and DYDC2, Figure 4A) on the growth of LNCaP cells in androgen-deprived medium. Each siRNA was transfected into LNCaP cells that were subsequently maintained in androgen-depleted medium. Two siRNAs, against ISFG8 and RTN1 enabled AD LNCaP cells to grow in androgen-deprived medium while two other siRNAs (C14orf147, DYDC2) and a control non-targeting siRNA had no effect (Figure 4C).

\section{Effects of IGSF8 knockdown on the expression of androgen receptor-regulated genes}

Because depletion of IGSF8 conferred the strongest AI growth on LNCaP cells, we analyzed in detail the effect of IGSF8 knockdown on the expression of AR target genes. We designed an independent set of siRNAs against IGSF8, transfected them into LNCaP cells, and determined the mRNA levels of AR target genes after 6 days in androgen-depleted medium. Two different IGSF8-targeting siRNAs yielded greater than 90\% IGSF8 mRNA depletion (Figure 5A). Both of these siRNAs also significantly upregulated endogenous mRNA levels of KLK2, KLK3 and TMPRSS2 in androgen-deprived LNCaP cells, while neither had a significant effect on FKBP5 expression (Figure 5B). To test whether AR is involved in IGSF8-dependent activation of endogenous genes we depleted IGSF8 and AR simultaneously. Co-transfection of IGSF8-2 siRNA and AR siRNA suppressed the ability of the IGSF8 siRNA to induce KLK2 and KLK3 expression (Figure 5C) indicating that the effect of IGSF8 was exerted through AR. Several of the siRNAs that affected the expression of AR targets in our screen targeted the tetraspanin protein CD9 that physically interacts with IGSF8 [12]. Curiously, however, CD9 belonged to the second class of AR regulators, as its knockdown decreased the expression of several AR target genes, including KLK2, KLK3 and TMPRSS2 (Figure 4A). As shown in Figure. 5D, siRNA-mediated depletion of CD9 downregulated the expression of KLK2 and KLK3 when used either alone or in combination with IGSF8 shRNA (Figure 5D). To further elucidate the effects of IGSF8 depletion on AR, we analyzed the expression of the AR protein in IGSF8 knockdown cells. IGSF8 knockdown strongly induced PSA expression (Figure 6A), it affected neither the expression (Figure 6A, 6B) nor the nuclear localization of the AR protein (Figure 6B). Finally, the androgen receptor antagonist enzalutamide drastically inhibited the induction of both KLK2 and PSA by IGS 8 knockdown, with only minor effects on the expression of AR and IGSF8 (Figure 6C), indicating that the effect of IGSF8 knockdown was mediated by AR.

Our data show that a subset of known androgenresponsive genes is upregulated by IGSF8 knockdown. To compare the transcriptomic effects of IGSF8 and AR, we analyzed gene expression profiles by microarrays using (i) LNCaP cells with IGSF8 knockdown in androgen-depleted medium; (ii) LNCaP cells stimulated with $10 \mathrm{pM}$ of R1881 for 24 hours; (iii) cells transfected with control siRNA in androgen-depleted medium; and (iv) untreated LNCaP cells in androgendepleted medium. $2357(7.1 \%)$ and 1625 (5\%) genes were significantly $(>1.4$ fold, $P<0.05)$ affected by R1881 treatment or IGSF8 knockdown, respectively. Strikingly, 34\% of R1881-regulated genes and 49\% of IGSF8 siRNA-responsive genes were regulated by both R1881 and IGSF8 siRNA. 55 genes were upregulated and 157 downregulated by both androgen and IGSF8 knockdown (Figure 7A, Supplementary Table S6). The majority of genes that were induced both by androgen and by IGSF8 shRNA are well-known AR targets, including KLK3(PSA), KLK2, KLK4, PPAP2A, C19orf48, cdc2, and NFKB2 [13-16]. Many AR targets 


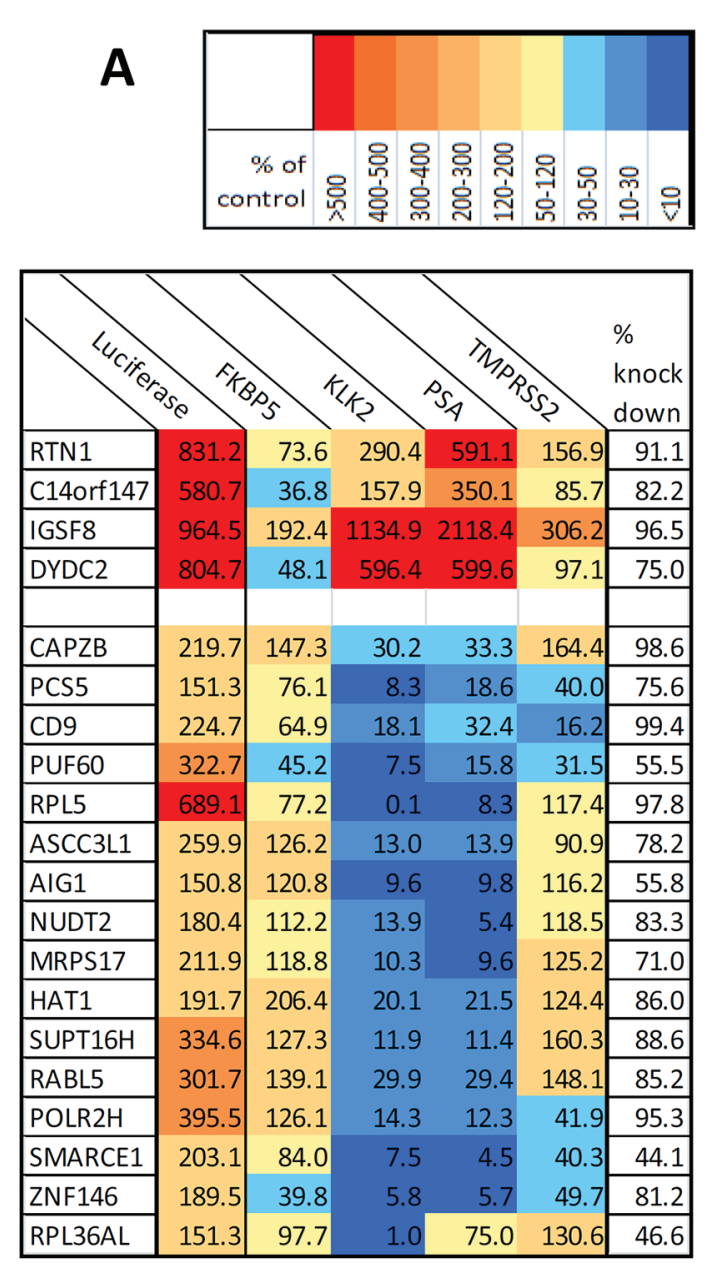

B

\begin{tabular}{|l|c|l|}
\hline \multicolumn{1}{|c|}{ GO categories } & $\begin{array}{c}\text { No of } \\
\text { genes }\end{array}$ & \multicolumn{1}{|c|}{ Gene symbols } \\
\hline $\begin{array}{l}\text { regulation of } \\
\text { transcription }\end{array}$ & 5 & $\begin{array}{l}\text { SMARCE1, ZNF146, } \\
\text { SUPT16H, HAT1, PUF60 }\end{array}$ \\
\hline ribonucleoprotein & 4 & $\begin{array}{l}\text { MRPS17, RPL5, PUF60, } \\
\text { RPL36AL }\end{array}$ \\
\hline transmembrane & 5 & $\begin{array}{l}\text { CD9, IGSF8, } \\
\text { C14ORF147, AIG1, RTN1 }\end{array}$ \\
\hline
\end{tabular}

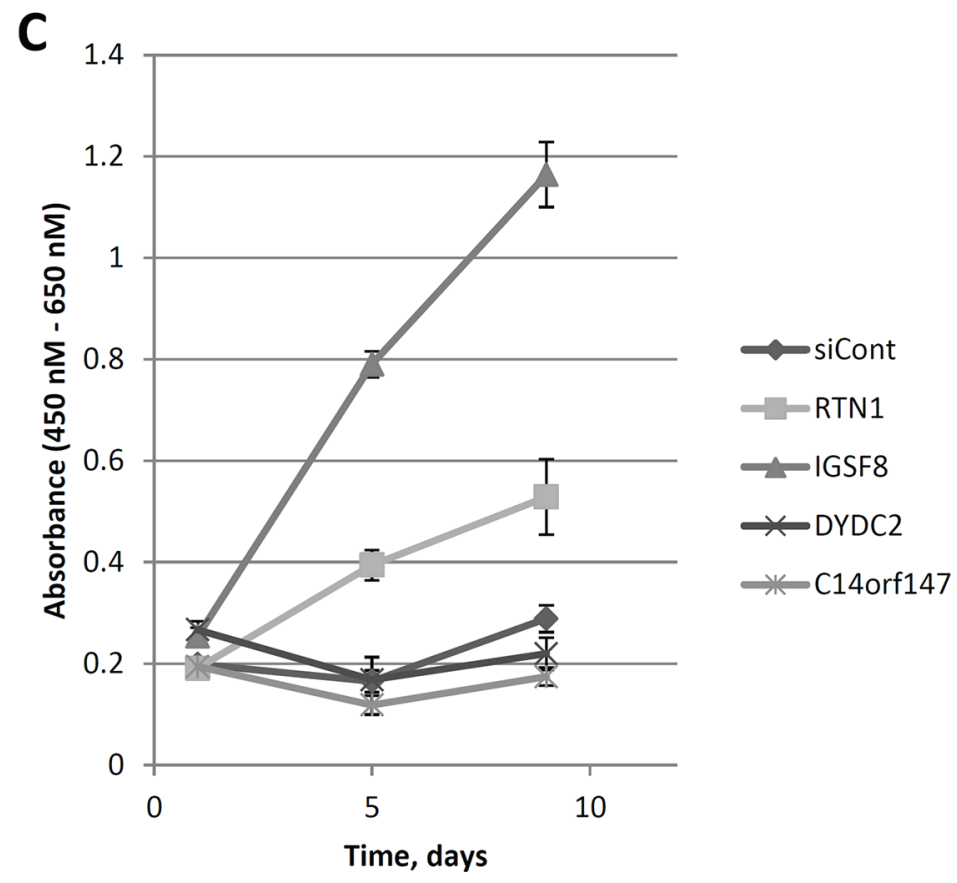

Figure 4: New regulators of androgen-responsive genes identified in the functional screening. A. Two groups of siRNA regulators were discovered: androgen independent activators and inhibitors of androgen responsive genes. The expression of 4 known androgen-responsive genes (KLF3 (PSA), KLK2, FKBP5 and TMPRSS2) was measured following transfection of selected siRNAs (at $5 \mathrm{~nm}$ ) into LNCaP cells in triplicates (see Figure 2). Cells were cultured in androgen-free conditions for 6 days. mRNA was purified and subjected to QPCR analysis. Table represents the levels of gene expression as percentages compared to control (the description of genes is presented in Supplementary Table S5). First column represents the effect of selected siRNAs on expression of luciferase in PrbLuc-LNCaP cells (in triplicate) B. Three GO categories enriched in the validated group of genes. C. Screen-selected siRNAs enable proliferation of LNCaP cells under hormone-free conditions. LNCaP cells were transfected with siRNAs as shown and cultured under androgen-free conditions. The number of viable cells was determined using spectrophotometric quantification of cell proliferation by WST1 assay. The plot represents the mean of six independent transfections $+/-$ SD.

affected by IGSF8 knockdown are known positive and negative regulators of cancer cell proliferation and survival. For example, cdc2 [17-19] and NFKB2 [20-22] enhance androgen-independent growth, and HMGCS2 [23], PIK3AP1 [24], ABCC4 [25], SLC1A5 [26], CYP3A5 [27] genes are associated with PCa progression. Furthermore, many genes downregulated by IGSF 8 knockdown are markers of neuroendocrine differentiation (OPRK1 [28, 29], PNMA2 [30], IGFBP3 [31]), cell-adhesion proteins (PCDHB10, PCDHB15, PCDHB8, PCDHB16, PCDHB18, PCDHB12,
PCDHB4), targets of AR-regulated transcriptional repressor REST [32, 33], and genes associated with suppression of prostate and other cancers (SERPINI1 [34], ODZ2 [35], SI [36], TLR5 [37, 38], RNF180 [39], FBXL2 [40-42], TRIM45 [43]). A large cohort of genes was differentially regulated by IGSF8 knockdown and androgen (Figure 7B, Supplementary Table S6). These include 292 genes upregulated by IGSF8 knockdown, while downregulated by R881 including pro-oncogenic genes (VAV3 [44-47], REG4 [48, 49], SYP2 [50], ZNF706 [51, 52], SHC4 [53]) 
A

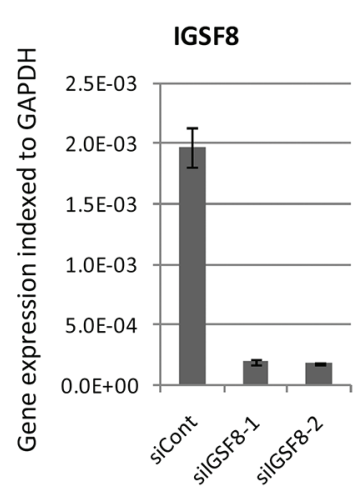

B
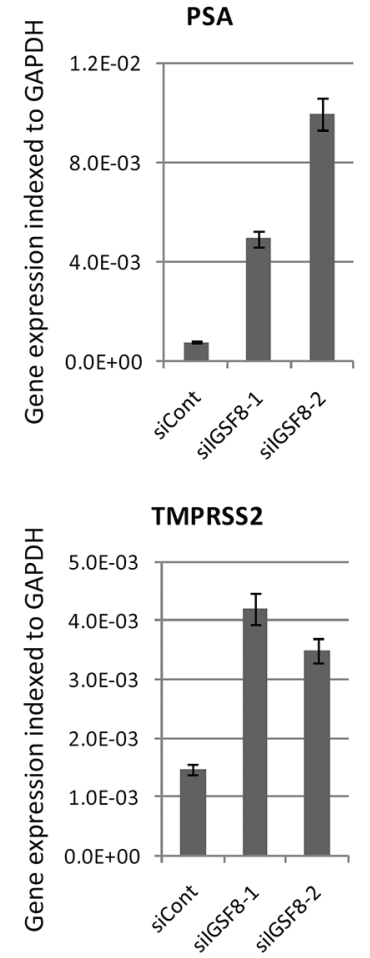

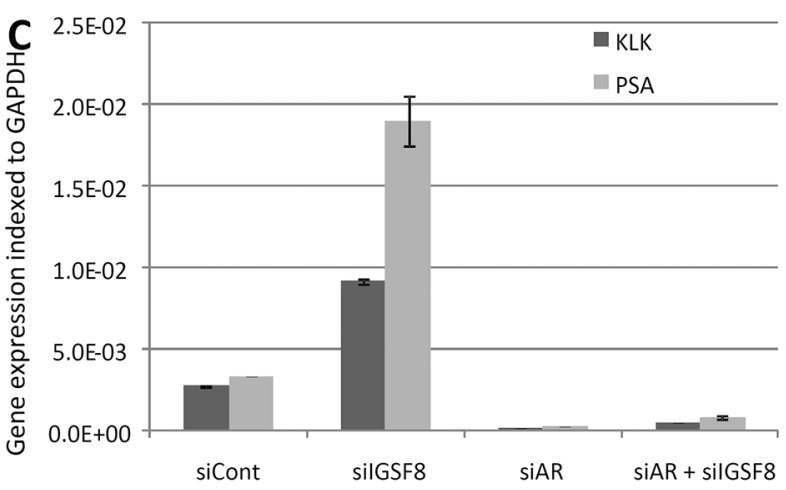

KLK2

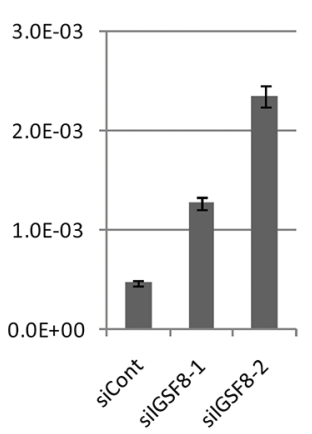

FKBP5

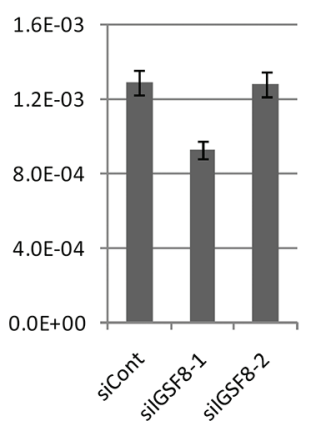

D
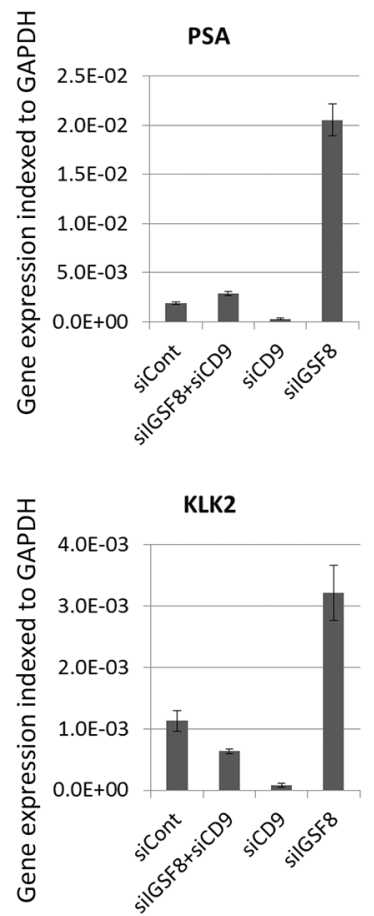

Figure 5: siRNA-mediated depletion of IGSF8 activates the expression of androgen responsive genes. A. Two different siRNAs efficiently inhibit expression of IGSF8 gene (QPCR analysis). B. LNCaP cells were transfected with IGSF8-targeting or control siRNAs $(5 \mathrm{nM})$ and cultured in hormone-free conditions for 6 days. Expression of androgen responsive genes was analyzed by QPCR. The results represents mean of 3 independent experiments +/- SD. C. Effect of the IGSF8 knockdown is AR-dependent. LNCaP cells were transfected with control, IGSF8 or AR siRNAs and cultured in hormone-free conditions for 6 days. Expression of androgen responsive genes was analyzed by QPCR. D. Effects of the IGSF8 knockdown depend on the expression of CD9. LNCaP cells were transfected with control, IGSF8 or CD9 siRNAs and cultured in hormone-free conditions for 6 days. Expression of androgen responsive genes was analyzed by QPCR. All QPCR results represent mean of 3 independent experiments +/- SD.

and biomarkers of PCa progression (PLA2G2A [54], CLU [55]). 298 genes were downregulated by IGSF8 knockdown while upregulated by R1881 including a cluster of UDP glucuronosyltransferase 2 family genes (UGT2B7, UGT2B17, UGT2B15, UGT2B11, UGT2B10, UGT2B4, UGT2B28, UGT2B7). UGT2B enzymes are mainly responsible for DHT degradation in prostate tissues [56-58]. The main triggers of androgen degradation, UGT2B17 and UGT2B15, were shown to be upregulated by activated AR [59], while they were drastically ( $>20$-fold) downregulated by IGSF8 knockdown. The expression levels of UGT2B17 and UGT2B15 were verified by QPCR in LNCaP with IGSF8 knockdown (with 2 independent siRNAs) (Supplementary Figure S3).

Potential alterations of the IGSF8 gene across various human cancers were analyzed using cBioPortal [60] (Figure 7C). IGSF8 is amplified in a majority of cancer types, except prostate cancers, where homozygous deletions were detected in $2 \%$ of analyzed samples (in 5 out of 244 samples of prostate adenocarcinomas) (Figure 7C). 
A

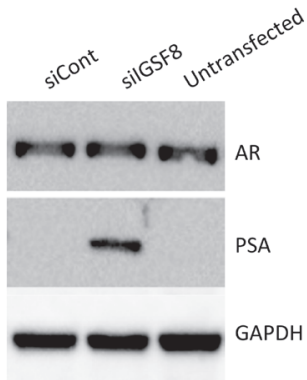

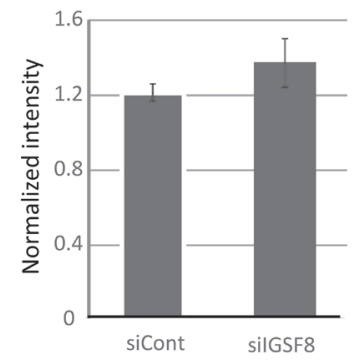

B

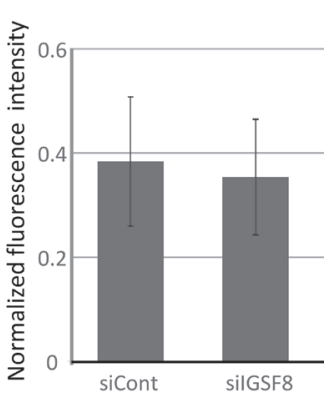

C
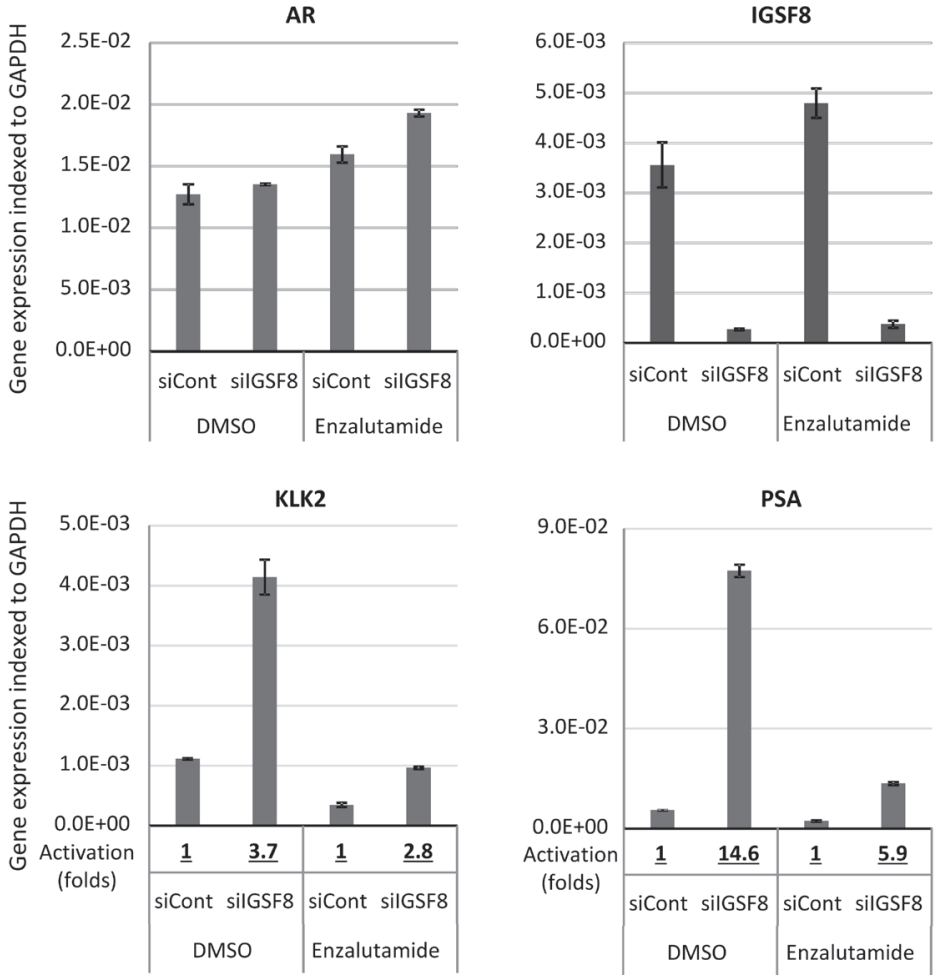

Figure 6: IGSF8 knockdown effects is dependent of AR but does not change AR expression. A. LNCaP cells were transfected with control or IGSF8-targeting siRNAs $(5 \mathrm{nM})$ and cultured in hormone-free conditions for 6 days. Expression of AR and PSA was analyzed by immunoblotting. Quantification of AR signal intensity normalized to GAPDH signal is shown on the right, relative to AR level of untransfected LNCaP cells (mean of 3 independent experiments +/- SD). B. LNCaP were transfected as above, followed by fixation and immunostaining with DAPI and anti-AR antibodies. Images were taken and nuclear staining was quantified. The results represent average quantification of the AR to DAPI ratio of fluorescence intensity (30 nuclei per siRNA) $+/-$ SD. C. LNCaP cells were transfected as in A and cultured in hormone-free conditions for 6 days in the presence of $10 \mu \mathrm{M}$ of Enzalutamide or DMSO. Gene expression was analyzed by QPCR. The results represent mean of 3 independent experiments $+/-$ SD.

\section{DISCUSSION}

CRPC is thought to be the consequence of dysregulated (hyperactive) androgen signaling in PCa cells that develops subsequent to chronic ADT. In this study, we developed a robust procedure for the identification of new co-regulators of AR that may participate in progression to CRPC. High throughput screens to identify co-regulators of hormone-dependent activation of AR transcriptional activity have been reported [61], but screens for the regulators of AR in hormone-free conditions have, to our knowledge, not been done before. Our procedure employed (i) high-complexity enzymatically generated shRNA libraries that target not only known but also uncharacterized transcripts (both coding and non-coding); (ii) FACS selection of library-infected cells with activated expression of a fluorescent reporter; and (iii) analysis of shRNA enrichment through massive parallel sequencing followed by target identification and validation. The elements of the screening procedure, including target identification through massive parallel sequencing of enzymaticallygenerated shRNA libraries, were described previously [4]. The combination of the key elements we developed allows for a robust and cost effective screening that can be used 
A
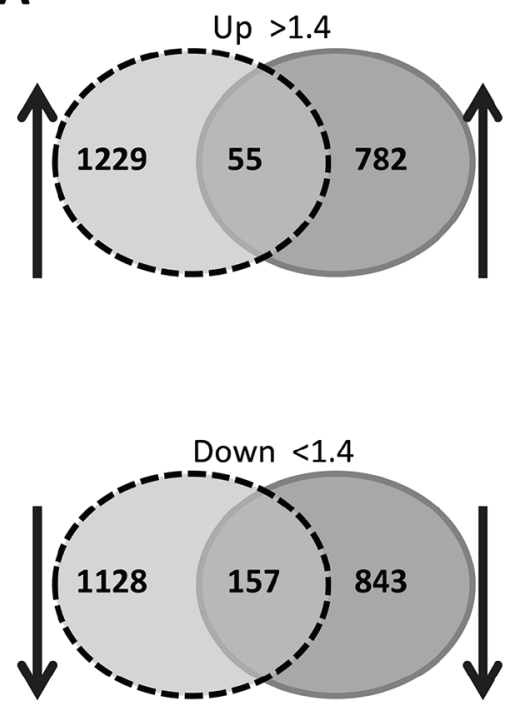

C

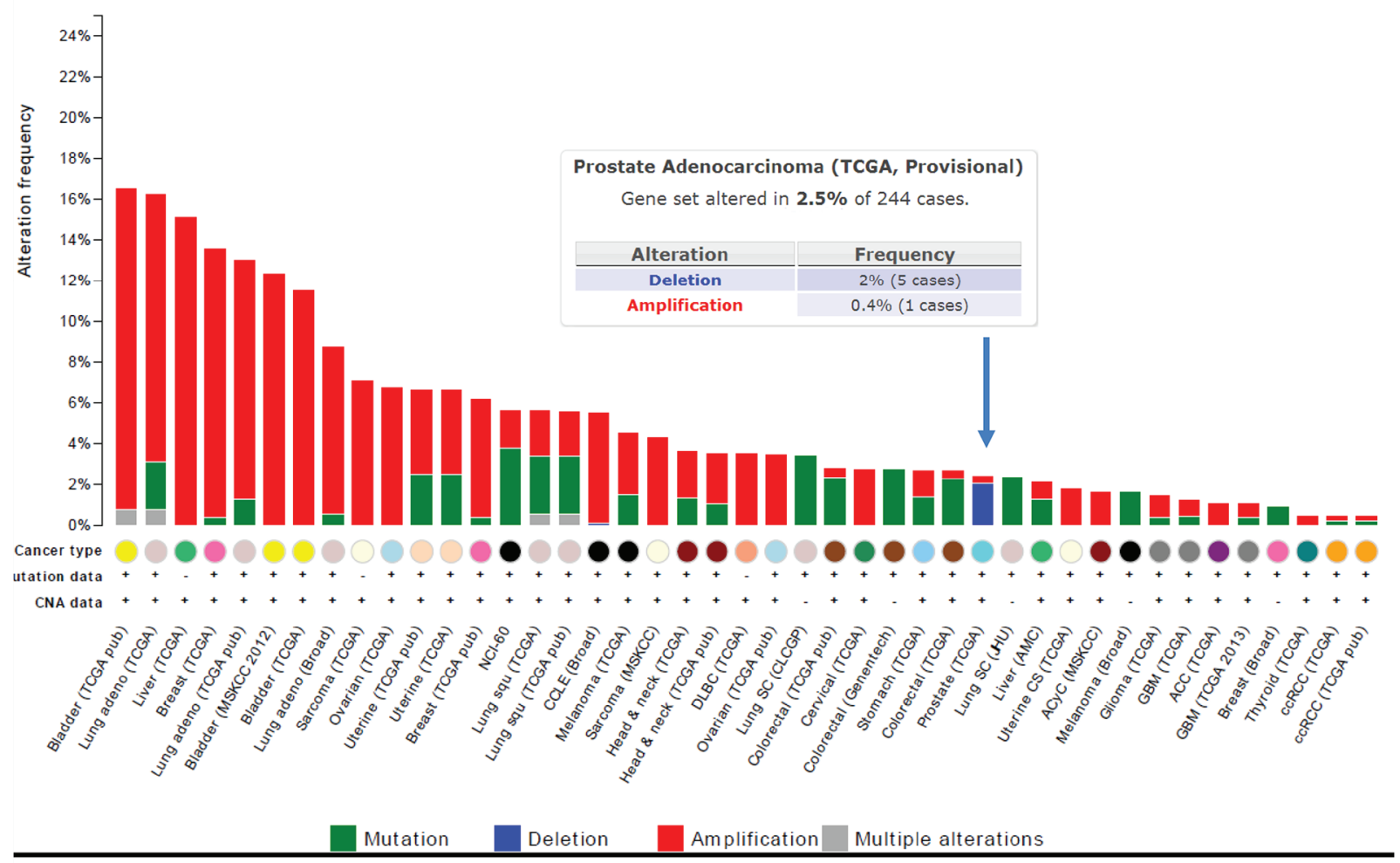

B
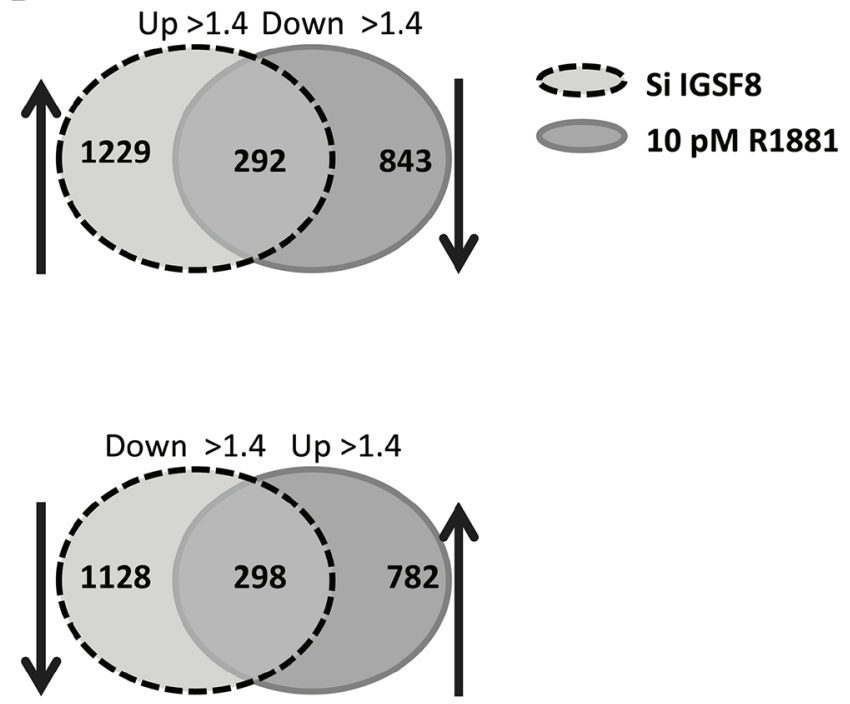
other 16 downregulated endogenous gene expression. The opposite effects of the latter siRNAs on the modified probasin promoter and endogenous genes parallel the reported effects on promoter-dependent activity of previously described co-regulators of AR and other steroid-hormone receptors $[9,62,63]$. In particular, the knockdown of components of the proteosome 19S subunit strongly activates expression from probasin promoter and strongly inhibits the expression of KLK2 and KLK3 in agreement with previous reports $[64,65]$. The pleotropic effect of proteosomal inhibition on gene expression causing either upregulation or downregulation of different groups of genes was shown for other steroid hormone receptors (glucocorticoid and estrogen receptors) [66-68].

Our target enrichment list included five genes associated with chromatin remodeling to a transcriptionally active state or with the transcription process (HAT1, SUPT16H and SMARCE1, POLR2H, ZNF146), a cluster of five RNA/ribonucleoprotein binding proteins (PUF60, RPL36AL, ASCC3L1, MRPS17 and RPL5), three genes encoding transmembrane proteins (RTN1, IGSF8, CD9) and two genes associated with GTPase signaling activities (AIG1, RABL5) (Figure 4B). Analysis of the association network of identified genes (Supplementary Figure S1) suggests potential mechanisms of activation of the expression of androgen-responsive genes by DYDC2, RTN1 and C14orf147.

RTN1 (reticulon 1 or neuroendocrine specific protein), knockdown of which enables androgenindependent proliferation of LNCaP cells, is a neuroendocrine cell specific protein, localized in endoplasmic reticulum [69]. RTN1 was shown to interact with HDAC8 [70], a multifunctional histone deacetylase with dual nuclear and cytoplasmic localization [71]. Knockdown of RTN1 could increase the nuclear pool of HDAC8. Nuclear HDAC8 was shown to regulate activities of transcription factors, including nuclear hormone receptors [72]. C14orf147 (serine palmitoyltransferase, Small Subunit A, SPTSSA) is a regulatory subunit of serine palmitoyltransferase (SPT) [73].SPT (localized in endoplasmic reticulum) is the first enzyme of the ER-localized ceramide biosynthesis pathway [74]. Ceramide was shown to inhibit $\mathrm{AR}$ activity and androgen independent growth of PCa cells through activation of protein phosphatase 2A (PP2A) [75]. Depletion of SPTSSA inhibits activity of SPT [76] and decreases ceramide accumulation [77], which in turn may cause partial inhibition of PP2A activity followed by AR activation. There is very little information about the function and activity of DPY30 Domain-Containing Protein 2 (DYDC2). The interaction network (Supplementary Figure S1) suggests that DYDC2 may influence AR activity through interaction with NME5 (NME/NM23 Family Member 5) or through HAT1 (histone acetyl transferase) activity.
We performed a more extensive characterization of IGSF8, the knockdown of which not only activates endogenous AR targets but also enables AI growth of LNCaP cells. The effect of IGSF8 knockdown was inhibited by the androgen antagonist Enzalutamide, indicating that it was mediated by AR. A close association of IGSF8 with androgen signaling is also indicated by a very high overlap between the sets of the genes that are affected either by the addition of androgen or by IGSF8 knockdown. IGSF8, an immunoglobulin family member, was originally identified as a binding partner of tetraspanin family proteins, CD9 and CD81, which modulates their activities [78]. There is evidence that IGSF 8 may affect membrane interaction and localization of tetraspanins [12, 79]. shRNAs targeting both CD9 and CD81 were enriched in our shRNA library selection. Knockdown of CD9 with individual siRNAs inhibited the expression of all tested AR-responsive genes (Figure $3 \mathrm{~A}$ ) but did not affect AI growth of LNCaP cells (data not shown). Based on our results showing that knockdown of CD9 inhibits the expression of AR-responsive genes, we hypothesize that tetraspanins are involved in the activation of ligand-independent activity of AR. There are several pathways downstream of CD9 which, when activated, could be involved in the regulation of AR activity. CD9 activates MAP kinase pathways [80-82], which in turn may lead to AR activation by MAPK phosphorylation [83-85]. Additionally, AR and CD9 share a common binding partner, ADAM10 that has a dual function as a metalloproteinase and a co-activator of AR dependent transactivation [86, 87]. Modulation of CD9 activity through IGSF8 knockdown could lead to $\mathrm{CD} 9$ relocalization from membrane to the nucleus and interaction with AR. Finally, other as yet unknown pathways could be involved in CD9 dependent regulation of AR activity due to the pleotropic effects of tetraspanins. The latter hypothesis is supported by recent results [88] showing nuclear localization of both CD9 and IGSF8 in breast carcinoma cells. That study showed that nuclear CD9 may be involved in regulation of mitosis, therefore IGSF8 inhibition may activate CD9 effects on both cell division and $\mathrm{AR}$ transcriptional regulation.

Expression level and outcome of CD9 activity in human tumors depends on the tumor origin. CD9 expression is correlated with poor prognosis of gastric cancer whereas the expression in melanomas, myelomas, and head and neck squamous carcinomas is associated with early stages of cancer progression and positive treatment outcome $[89,90]$. CD9 expression declined significantly as benign prostate epithelial cells progress from early malignancy to metastasis [91]. Recent findings suggest that the downregulation of CD9 expression is concomitant with the production of a truncated CD9 isoform through cancer specific gene fusion [92]. Moreover, the novel CD9 fusion genes in prostate cancer lack the IGSF8 binding epitope [93]. Thus it is tempting to speculate that the function of 
IGSF8 is linked to the suppression of androgen signaling in PCa cells expressing unaltered CD9. This is supported by evidence of IGSF8 deletions in prostate tumors. Both CD9 translocations and IGSF8 deletions are observed in $2-3 \%$ of prostate tumors. Therefore, activation of CD9 either by IGSF8 deletion or CD9 translocation could be involved in the development of CRPC.

Tumor suppressor activities of IGSF8 have been previously addressed in $\mathrm{PCa}$, although with respect to cell motility rather than AR signaling [94], and in glioblastomas [95]. The involvement of CD9 and IGSF8 in glioma progression is consistent with our findings in PCa: elevation of CD9 expression and downregulation of IGSF8 correlated with progression of malignant glioma $[95,96]$, Although IGSF8 is frequently downregulated in gliomas, cBioPortal does not show any rearrangements of IGSF8 in gliomas. It seems likely that, in spite of the rarity of IGSF8 deletion in prostate cancers, the level of IGSF8 protein may also be reduced in prostate tumors by epigenetic mechanisms.

Known mechanisms of transition from $\mathrm{AD}$ to $\mathrm{AI}$ growth in PCa include AR overexpression, AR mutations and expression of AR splice variants. There are, however, many examples of PCa cell lines or tumors with elevated AR signaling but without obvious changes in AR itself. Our results provide, to the best of our knowledge, the first examples of the transactivation of AR signaling and the acquisition of AI growth through the inhibition of specific genes. Other trans-repressors and trans-activators of AR signaling that can confer androgen independence can be identified through the approach developed in the present study. Analysis of such regulatory genes in clinical CRPC should greatly enrich our understanding of the mechanisms of androgen independence in prostate cancer and suggest new approaches to overcoming this major clinical problem.

\section{MATERIALS AND METHODS}

\section{Plasmids and vectors}

Vectors containing rat probasin promoter (ARR(2) PB) [3] were obtained from Dr. Robert J. Matusik (Vanderbilt University, Nashville, TN). The promoter was inserted into DsRed and luciferase reporter lentiviral vectors to create pLR-PRBp-DsRed-DR and pLLRMPRbp-Luc constructs correspondently (see construction details in Supplementary Methods). pLLCEmGFP lentiviral vector was previously described [97].

\section{Lentiviral infection}

Lentiviral transduction was done as described [4] using pCMV- $\triangle 8.9$ and pVSV-G packaging constructs. Vector plasmid, pCMV- $\Delta 8.9$, and pVSV-G DNA were mixed at a 5:4:1 ratio and cotransfected into 293FT cells cultured on polyethyleneimine-coated plates [98]. Lentivirus-containing supernatants were harvested thrice, at 24, 48 and 72 hours after transfection.

\section{Cell culture}

Human PCa cell lines LNCaP and PC3 from the ATCC (Manassas, VA) were maintained in RPMI-1640 medium with $10 \%$ fetal bovine serum (FBS) or switched to phenol red-free RPMI-1640 with 10\% charcoalstripped FBS (CS-FBS) for androgen-depleted conditions as previously described [99]. The 293FT cells from Life Technologies (Grand Island, NY) were maintained in DMEM with 10\% FBS. R1881 (methyltrienolone), was obtained from PerkinElmer Life Sciences (Boston, MA). Reporter cell lines Prb-DsRed-LNCaP and Prb-LucLNCaP were prepared as described in Supplementary Methods.

\section{Construction of normalized shRNA libraries}

The shRNA library originating from MCF7 breast carcinoma cDNA was previously reported [4]. Preparation of the prostate-specific shRNA library was similar to previously described procedure [4]. (See construction details in Supplementary Methods.)

\section{Library transduction, selection for activation of probasin promoter and analysis of selection results}

shRNA libraries were transduced into Prb-DsRed$\mathrm{LNCaP}$ reporter cells. The infection rate (as determined by qPCR analysis of integrated provirus) was $95 \%$. The total of $10^{8}$ cells were plated at a density of $10^{7}$ cells per plate, and cultured in androgen-free conditions (phenol red-free RPMI-1640 with 10\% CS-FBS) for 10 days. $25 \%$ of the cells were collected for DNA purification, the rest were subjected to FACS sorting to collect the total of $6 \times 10^{5}$ DsRed positive cells. DNA was purified from unsorted and DsRed positive cells. The shRNA inserts were amplified by two rounds of PCR from genomic DNA preparations of the unsorted and DsRed positive cells and sequenced using 454 Sequencer (Roche). shRNA sequence attribution was done as previously described [4, 97].

\section{Screening of siRNAs and luciferase activity assay}

Four siRNAs per gene, obtained from Qiagen Human Whole Genome siRNA set 1.0, were transfected into Prb-Luc-LNCaP cells in PEI coated 96-well plates (10, 000 cells per well) [98], in triplicate, at $5 \mathrm{nM}$ of siRNA per well using Silentfect transfection reagent (BioRad) and reverse transfection procedure per Qiagen (Highperfect) instructions. A cytotoxic mixture of siRNAs 
derived from several essential genes (Qiagen, All-star cell death Hs siRNA, \#1027298) and anti-luciferase siRNA (Qiagen, Luciferase GL3 siRNA, \# 1022073), were used as positive controls, and siRNA targeting no known genes (Qiagen, Negative Control siRNA \#1022076) was used as a negative control. Cells were cultured in phenol red-free RPMI-1640 with 10\% CS-FBS 6 days post transfection, washed with PBS and lysed for 60 min with $100 \mu \mathrm{L}$ of cell lysis buffer $(0.22 \% \mathrm{NaCl}, 0.15 \%$ Saponin, $1 \mathrm{mM}$ EDTA) containing $0.5 \mu \mathrm{g} / \mathrm{mL}$ Hoechst 33342 (Polysciences Inc, Warrington, PA, \#23491-52-3) that stains cellular DNA. Relative cell numbers were determined by Hoechst 33342 fluorescence. Luciferase activity was determined with prepared luciferase reporter reagents [100]. The ratio of firefly luciferase activity/Hoechst 33342 fluorescence was scored as normalized luciferase activity.

\section{Cell proliferation assay}

LNCaP cells were transfected with siRNAs in PEI coated 96-well plates (2000 cells per well) as described above. Cell proliferation was analyzed by WST-1 assay with WST-1 cell proliferation reagent (Roche Lifescience, Indianapolis, IN).

\section{QPCR and microarray analysis of gene expression}

LNCaP cells were transfected with siRNAs against indicated genes (Supplementary Table S7) as described above. Total cellular RNA was purified with either RNeasy kit (Qiagen) or TRIzol (Life Technologies, Grand Island, NY). Microarray analysis using Affymetrix Exon 1.0ST human oligonucleotide arrays was conducted by Ordway Research Institute's Microarray Facility. Microarray data were analyzed using GeneSpring GX (Agilent, Santa Clara CA). For quantitative PCR (qPCR) analysis, cDNA was prepared using Maxima First Strand cDNA Synthesis (Thermo Scientific, Waltham, MA). Gene expression was measured by QPCR, with gene specific primers and GAPDH or RPL13A as normalization standards (primer sequences are presented in Supplementary Table S8) using RT2 SYBR Green qPCR Master Mixes (Qiagen).

\section{Protein measurement}

Protein levels were assayed by immunoblotting with appropriate antibodies. The following antibodies were used: rabbit anti AR (, H-280, sc-13062, Santa Cruz, CA), rabbit anti PSA (K92110R, BioDesign Saint-Priest, France) and mouse anti GAPDH (6C5, sc-32233, Santa Cruz, CA). Appropriate secondary antibodies conjugated to horseradish peroxidase were used, and membranes were developed using an enhanced chemilluminescence reagent (Thermo Fisher Scientific Inc., Rockford, IL). Images were obtained with ChemDoc Touch imaging system (Bio-Rad, Hercules, CA ). Band intensities were measured using Image Lab (Bio-Rad, Hercules, CA).

\section{Immunofluorescence}

Cells cultured on glass coverslips (Bellco Glass, Vineland, NJ) were fixed with $4 \%$ paraformaldehyde in PBS for 20 minutes at room temperature and permeabilized with $0.5 \%$ Triton $\mathrm{X}-100$ in PBS for 3 minutes. The coverslips were incubated with rabbit antiAR H-280 antibodies and DAPI (Life Technologies, CA). The secondary antibody was labeled with Alexa Fluor 488 (Life Technologies, CA). Fluorescence images were acquired with a 40x/0.60 n.a. LUCPlan FLN objective on an Olympus IX81 microscope. Hamamatsu C10600 camera gain and exposure time settings were controlled with Metamorph Basic. Nuclear fluorescence intensities were measured with ImageJ (NIH).

\section{ACKNOWLEDGMENTS}

We thank Greg Hurteau for excellent technical assistance. This study was supported by AFPE PreDoctoral Fellowship (DO), grant W81XWH-08-1-0070 from the Department of Defense Prostate Cancer Research Program, NIGMS grant 1P20GM109091-01, NIH grant P30 GM103336 to the Center for Colon Cancer Research at the University of South Carolina and SC INBRE pilot award (MS), Cancer Research Society, Canada (RB) and NIH grants R33 CA95996 and R01 AG028687 (IBR).

\section{REFERENCES}

1. Silberstein JL, Pal SK, Lewis B, Sartor O. Current clinical challenges in prostate cancer. Translational Andrology and Urology. 2013; 2:122-136.

2. Nyquist MD, Dehm SM. Interplay between genomic alterations and androgen receptor signaling during prostate cancer development and progression. Hormones \& cancer. 2013; 4:61-69.

3. Zhang J, Thomas TZ, Kasper S, Matusik RJ. A small composite probasin promoter confers high levels of prostatespecific gene expression through regulation by androgens and glucocorticoids in vitro and in vivo. Endocrinology. 2000; 141:4698-4710.

4. Shtutman M, Maliyekkel A, Shao Y, Carmack CS, Baig M, Warholic N, Cole K, Broude EV, Harkins TT, Ding Y, Roninson IB. Function-based gene identification using enzymatically generated normalized shRNA library and massive parallel sequencing. ProcNatlAcadSciUSA. 2010; 107:7377-7382.

5. Kang Z, Pirskanen A, Janne OA, Palvimo JJ. Involvement of proteasome in the dynamic assembly of the androgen receptor transcription complex. JBiolChem. 2002; 277: 48366-48371.

6. Chymkowitch P, Le May N, Charneau P, Compe E, Egly JM. The phosphorylation of the androgen receptor by 
TFIIH directs the ubiquitin/proteasome process. The EMBO journal. 2011; 30:468-479.

7. Augello MA, Hickey TE, Knudsen KE. FOXA1: master of steroid receptor function in cancer. The EMBO journal. 2011; 30:3885-3894.

8. Hagan CR, Lange CA. Molecular determinants of contextdependent progesterone receptor action in breast cancer. BMC medicine. 2014; 12:32.

9. Lonard DM, O'Malley BW. Nuclear receptor coregulators: modulators of pathology and therapeutic targets. Nature reviews Endocrinology. 2012; 8:598-604.

10. Magee JA, Chang LW, Stormo GD, Milbrandt J. Direct, androgen receptor-mediated regulation of the FKBP5 gene via a distal enhancer element. Endocrinology. 2006; 147:590-598.

11. Wang Q, Li W, Liu XS, Carroll JS, Janne OA, Keeton EK, Chinnaiyan AM, Pienta KJ, Brown M. A hierarchical network of transcription factors governs androgen receptordependent prostate cancer growth. Molecular cell. 2007; 27:380-392.

12. Yang XH, Kovalenko OV, Kolesnikova TV, Andzelm MM, Rubinstein E, Strominger JL, Hemler ME. Contrasting effects of EWI proteins, integrins, and protein palmitoylation on cell surface CD9 organization. JBiolChem. 2006; 281:12976-12985.

13. Lai J, Myers SA, Lawrence MG, Odorico DM, Clements JA. Direct progesterone receptor and indirect androgen receptor interactions with the kallikrein-related peptidase 4 gene promoter in breast and prostate cancer. Molecular cancer research: MCR. 2009; 7:129-141.

14. Ulrix W, Swinnen JV, Heyns W, Verhoeven G. Identification of the phosphatidic acid phosphatase type $2 \mathrm{a}$ isozyme as an androgen-regulated gene in the human prostatic adenocarcinoma cell line LNCaP. The Journal of biological chemistry. 1998; 273:4660-4665.

15. Marks LS, Mazer NA, Mostaghel E, Hess DL, Dorey FJ, Epstein JI, Veltri RW, Makarov DV, Partin AW, Bostwick DG, Macairan ML, Nelson PS. Effect of testosterone replacement therapy on prostate tissue in men with late-onset hypogonadism: a randomized controlled trial. JAMA: the journal of the American Medical Association. 2006; 296:2351-2361.

16. Romanuik TL, Wang G, Holt RA, Jones SJ, Marra MA, Sadar MD. Identification of novel androgen-responsive genes by sequencing of LongSAGE libraries. BMC genomics. 2009; 10:476.

17. Gregory CW, Hamil KG, Kim D, Hall SH, Pretlow TG, Mohler JL, French FS. Androgen receptor expression in androgen-independent prostate cancer is associated with increased expression of androgen-regulated genes. Cancer research. 1998; 58:5718-5724.

18. Gregory CW, Johnson RT Jr, Presnell SC, Mohler JL, French FS. Androgen receptor regulation of G1 cyclin and cyclin-dependent kinase function in the CWR human prostate cancer xenograft. Journal of andrology. 2001; 22:537-548.

19. Willder JM, Heng SJ, McCall P, Adams CE, Tannahill C, Fyffe G, Seywright M, Horgan PG, Leung HY, Underwood MA, Edwards J. Androgen receptor phosphorylation at serine 515 by Cdk1 predicts biochemical relapse in prostate cancer patients. British journal of cancer. 2013; 108:139-148.

20. Lessard L, Saad F, Le Page C, Diallo JS, Peant B, Delvoye N, Mes-Masson AM. NF-kappaB2 processing and p52 nuclear accumulation after androgenic stimulation of LNCaP prostate cancer cells. Cellular signalling. 2007; 19:1093-1100.

21. Nadiminty N, Chun JY, Lou W, Lin X, Gao AC. NF-kappaB2/p52 enhances androgen-independent growth of human $\mathrm{LNCaP}$ cells via protection from apoptotic cell death and cell cycle arrest induced by androgen-deprivation. The Prostate. 2008; 68:1725-1733.

22. Nadiminty N, Tummala R, Liu C, Yang J, Lou W, Evans CP, Gao AC. NF-kappaB2/p52 induces resistance to enzalutamide in prostate cancer: role of androgen receptor and its variants. Molecular cancer therapeutics. 2013; 12:1629-1637.

23. Saraon P, Cretu D, Musrap N, Karagiannis GS, Batruch I, Drabovich AP, van der Kwast T, Mizokami A, Morrissey C, Jarvi K, Diamandis EP. Quantitative proteomics reveals that enzymes of the ketogenic pathway are associated with prostate cancer progression. Molecular \& cellular proteomics: MCP. 2013; 12:1589-1601.

24. Koutros S, Schumacher FR, Hayes RB, Ma J, Huang WY, Albanes D, Canzian F, Chanock SJ, Crawford ED, Diver WR, Feigelson HS, Giovanucci E, Haiman CA, Henderson BE, Hunter DJ, Kaaks R, et al. Pooled analysis of phosphatidylinositol 3-kinase pathway variants and risk of prostate cancer. Cancer research. 2010; 70:2389-2396.

25. Ho LL, Kench JG, Handelsman DJ, Scheffer GL, Stricker PD, Grygiel JG, Sutherland RL, Henshall SM, Allen JD, Horvath LG. Androgen regulation of multidrug resistance-associated protein 4 (MRP4/ABCC4) in prostate cancer. The Prostate. 2008; 68:1421-1429.

26. Li R, Younes M, Frolov A, Wheeler TM, Scardino P, Ohori M, Ayala G. Expression of neutral amino acid transporter ASCT2 in human prostate. Anticancer research. 2003; 23:3413-3418.

27. Fernandez P, Zeigler-Johnson CM, Spangler E, van der Merwe A, Jalloh M, Gueye SM, Rebbeck TR. Androgen Metabolism Gene Polymorphisms, Associations with Prostate Cancer Risk and Pathological Characteristics: A Comparative Analysis between South African and Senegalese Men. Prostate cancer. 2012; 2012:798634.

28. Buhler P, Fischer T, Wolf P, Gierschner D, SchultzeSeemann W, Wetterauer U, Elsasser-Beile U. Comparison of gene expression in $\mathrm{LNCaP}$ prostate cancer cells after treatment with bicalutamide or 5-alpha-reductase inhibitors. Urologia internationalis. 2010; 84:203-211. 
29. Romanuik TL, Wang G, Morozova O, Delaney A, Marra MA, Sadar MD. LNCaP Atlas: gene expression associated with in vivo progression to castration-recurrent prostate cancer. BMC medical genomics. 2010; 3:43.

30. Leja J, Essaghir A, Essand M, Wester K, Oberg K, Totterman TH, Lloyd R, Vasmatzis G, Demoulin JB, Giandomenico V. Novel markers for enterochromaffin cells and gastrointestinal neuroendocrine carcinomas. Modern pathology: an official journal of the United States and Canadian Academy of Pathology, Inc. 2009; 22:261-272.

31. Freemantle SJ, Kerley JS, Olsen SL, Gross RH, Spinella MJ. Developmentally-related candidate retinoic acid target genes regulated early during neuronal differentiation of human embryonal carcinoma. Oncogene. 2002; 21:2880-2889.

32. Tan YP, Li S, Jiang XJ, Loh W, Foo YK, Loh CB, Xu Q, Yuen WH, Jones M, Fu J, Venkatesh B, Yu WP. Regulation of protocadherin gene expression by multiple neuronrestrictive silencer elements scattered in the gene cluster. Nucleic acids research. 2010; 38:4985-4997.

33. Svensson C, Ceder J, Iglesias-Gato D, Chuan YC, Pang ST, Bjartell A, Martinez RM, Bott L, Helczynski L, Ulmert D, Wang Y, Niu Y, Collins C, Flores-Morales A. REST mediates androgen receptor actions on gene repression and predicts early recurrence of prostate cancer. Nucleic acids research. 2014; 42:999-1015.

34. Yamanaka S, Olaru AV, An F, Luvsanjav D, Jin Z, Agarwal R, Tomuleasa C, Popescu I, Alexandrescu S, Dima S, Chivu-Economescu M, Montgomery EA, Torbenson M, Meltzer SJ, Selaru FM. MicroRNA-21 inhibits Serpinil, a gene with novel tumour suppressive effects in gastric cancer. Digestive and liver disease: official journal of the Italian Society of Gastroenterology and the Italian Association for the Study of the Liver. 2012; 44:589-596.

35. Vinatzer U, Gollinger M, Mullauer L, Raderer M, Chott A, Streubel B. Mucosa-associated lymphoid tissue lymphoma: novel translocations including rearrangements of ODZ2, JMJD2C, and CNN3. Clinical cancer research: an official journal of the American Association for Cancer Research. 2008; 14:6426-6431.

36. Rodriguez D, Ramsay AJ, Quesada V, Garabaya C, Campo E, Freije JM, Lopez-Otin C. Functional analysis of sucrase-isomaltase mutations from chronic lymphocytic leukemia patients. Human molecular genetics. 2013; 22:2273-2282.

37. Shi M, Yao Y, Han F, Li Y, Li Y. MAP1S controls breast cancer cell TLR5 signaling pathway and promotes TLR5 signaling-based tumor suppression. PloS one. 2014; 9:e86839.

38. Zhou H, Chen JH, Hu J, Luo YZ, Li F, Xiao L, Zhong MZ. High expression of Toll-like receptor 5 correlates with better prognosis in non-small-cell lung cancer: an anti-tumor effect of TLR5 signaling in non-small cell lung cancer. Journal of cancer research and clinical oncology. 2014; 140:633-643.

39. Cheung KF, Lam CN, Wu K, Ng EK, Chong WW, Cheng AS, To KF, Fan D, Sung JJ, Yu J. Characterization of the gene structure, functional significance, and clinical application of RNF180, a novel gene in gastric cancer. Cancer. 2012; 118:947-959.

40. Chen BB, Glasser JR, Coon TA, Mallampalli RK. FBXL2 is a ubiquitin E3 ligase subunit that triggers mitotic arrest. Cell cycle (Georgetown, Tex). 2011; 10:3487-3494.

41. Chen BB, Glasser JR, Coon TA, Mallampalli RK. Skpcullin-F box E3 ligase component FBXL2 ubiquitinates Aurora B to inhibit tumorigenesis. Cell death \& disease. 2013; 4:e759.

42. Chen BB, Glasser JR, Coon TA, Zou C, Miller HL, Fenton M, McDyer JF, Boyiadzis M, Mallampalli RK. F-box protein FBXL2 targets cyclin D2 for ubiquitination and degradation to inhibit leukemic cell proliferation. Blood. 2012; 119:3132-3141.

43. Shibata M, Sato T, Nukiwa R, Ariga T, Hatakeyama S. TRIM45 negatively regulates NF-kappaB-mediated transcription and suppresses cell proliferation. Biochemical and biophysical research communications. 2012; 423:104-109.

44. Hirai K, Nomura T, Yamasaki M, Inoue T, Narimatsu T, Chisato Nakada PD, Yoshiyuki Tsukamoto PD, Matsuura K, Sato F, Moriyama M, Mimata H. The Vav3 oncogene enhances the malignant potential of prostate cancer cells under chronic hypoxia. Urologic oncology. 2014; 32:101-109.

45. Peacock SO, Fahrenholtz CD, Burnstein KL. Vav3 enhances androgen receptor splice variant activity and is critical for castration-resistant prostate cancer growth and survival. Molecular endocrinology (Baltimore, Md). 2012; 26:1967-1979.

46. Lyons LS, Burnstein KL. Vav3, a Rho GTPase guanine nucleotide exchange factor, increases during progression to androgen independence in prostate cancer cells and potentiates androgen receptor transcriptional activity. Molecular endocrinology (Baltimore, Md). 2006; 20:1061-1072.

47. Dong Z, Liu Y, Lu S, Wang A, Lee K, Wang LH, Revelo M, Lu S. Vav3 oncogene is overexpressed and regulates cell growth and androgen receptor activity in human prostate cancer. Molecular endocrinology (Baltimore, Md). 2006; 20:2315-2325.

48. Bishnupuri KS, Sainathan SK, Bishnupuri K, Leahy DR, Luo Q, Anant S, Houchen CW, Dieckgraefe BK. Reg4induced mitogenesis involves Akt-GSK3beta-beta-CateninTCF-4 signaling in human colorectal cancer. Molecular carcinogenesis. 2014; 53:E169-180.

49. He XJ, Jiang XT, Ma YY, Xia YJ, Wang HJ, Guan TP, Shao QS, Tao HQ. REG4 contributes to the invasiveness of pancreatic cancer by upregulating MMP-7 and MMP-9. Cancer science. 2012; 103:2082-2091.

50. Ho JR, Chapeaublanc E, Kirkwood L, Nicolle R, Benhamou S, Lebret T, Allory Y, Southgate J, Radvanyi F, Goud B. Deregulation of Rab and Rab effector genes in bladder cancer. PloS one. 2012; 7:e39469.

51. Cheng L, Wang P, Yang S, Yang Y, Zhang Q, Zhang W, Xiao H, Gao H, Zhang Q. Identification of genes with a correlation between copy number and expression in gastric cancer. BMC medical genomics. 2012; 5:14. 
52. Colombo J, Fachel AA, De Freitas Calmon M, Cury PM, Fukuyama EE, Tajara EH, Cordeiro JA, VerjovskiAlmeida S, Reis EM, Rahal P. Gene expression profiling reveals molecular marker candidates of laryngeal squamous cell carcinoma. Oncology reports. 2009; 21:649-663.

53. Liu W, Peng Y, Tobin DJ. A new 12-gene diagnostic biomarker signature of melanoma revealed by integrated microarray analysis. PeerJ. 2013; 1:e49.

54. Oleksowicz L, Liu Y, Bracken RB, Gaitonde K, Burke B, Succop P, Levin L, Dong Z, Lu S. Secretory phospholipase A2-IIa is a target gene of the HER/HER2-elicited pathway and a potential plasma biomarker for poor prognosis of prostate cancer. The Prostate. 2012; 72:1140-1149.

55. Koltai T. Clusterin: a key player in cancer chemoresistance and its inhibition. OncoTargets and therapy. 2014; 7:447-456.

56. Barbier O, Belanger A. Inactivation of androgens by UDPglucuronosyltransferases in the human prostate. Best practice \& research Clinical endocrinology \& metabolism. 2008; 22:259-270.

57. Valentini A, Biancolella M, Amati F, Gravina P, Miano R, Chillemi G, Farcomeni A, Bueno S, Vespasiani G, Desideri A, Federici G, Novelli G, Bernardini S. Valproic acid induces neuroendocrine differentiation and UGT2B7 up-regulation in human prostate carcinoma cell line. Drug metabolism and disposition: the biological fate of chemicals. 2007; 35:968-972.

58. Belanger A, Pelletier G, Labrie F, Barbier O, Chouinard S. Inactivation of androgens by UDP-glucuronosyltransferase enzymes in humans. Trends in endocrinology and metabolism: TEM. 2003; 14:473-479.

59. Bao BY, Chuang BF, Wang Q, Sartor O, Balk SP, Brown M, Kantoff PW, Lee GS. Androgen receptor mediates the expression of UDP-glucuronosyltransferase 2 B15 and B17 genes. The Prostate. 2008; 68:839-848.

60. Gao J, Aksoy BA, Dogrusoz U, Dresdner G, Gross B, Sumer SO, Sun Y, Jacobsen A, Sinha R, LarssonE, Cerami E, Sander C, Schultz N. Integrative analysis of complex cancer genomics and clinical profiles using the cBioPortal. Science signaling. 2013; 6:pl1.

61. Imberg-Kazdan K, Ha S, Greenfield A, Poultney CS, Bonneau R, Logan SK, Garabedian MJ. A genome-wide RNA interference screen identifies new regulators of androgen receptor function in prostate cancer cells. Genome research. 2013; 23:581-591.

62. Wang Q, Li W, Zhang Y, Yuan X, Xu K, Yu J, Chen Z, Beroukhim R, Wang H, Lupien M, Wu T, Regan MM, Meyer CA, Carroll JS, Manrai AK, Janne OA, et al. Androgen receptor regulates a distinct transcription program in androgenindependent prostate cancer. Cell. 2009; 138:245-256.

63. van de Wijngaart DJ, Dubbink HJ, van Royen ME, Trapman J, Jenster G. Androgen receptor coregulators: recruitment via the coactivator binding groove. Molecular and cellular endocrinology. 2012; 352:57-69.

64. Lin HK, Altuwaijri S, Lin WJ, Kan PY, Collins LL, Chang C. Proteasome activity is required for androgen receptor transcriptional activity via regulation of androgen receptor nuclear translocation and interaction with coregulators in prostate cancer cells. The Journal of biological chemistry. 2002; 277:36570-36576.

65. Kang Z, Pirskanen A, Janne OA, Palvimo JJ. Involvement of proteasome in the dynamic assembly of the androgen receptor transcription complex. The Journal of biological chemistry. 2002; 277:48366-48371.

66. Kinyamu HK, Archer TK. Proteasome activity modulates chromatin modifications and RNA polymerase II phosphorylation to enhance glucocorticoid receptor-mediated transcription. Molecular and cellular biology. 2007; 27:4891-4904.

67. Deroo BJ, Rentsch C, Sampath S, Young J, DeFranco DB, Archer TK. Proteasomal inhibition enhances glucocorticoid receptor transactivation and alters its subnuclear trafficking. Molecular and cellular biology. 2002; 22:4113-4123.

68. Lee JH, Lee MJ. Emerging roles of the ubiquitinproteasome system in the steroid receptor signaling. Archives of pharmacal research. 2012; 35:397-407.

69. Senden NH, Timmer ED, Boers JE, van de Velde HJ, Roebroek AJ, Van de Ven WJ, Broers JL, Ramaekers FC. Neuroendocrine-specific protein C (NSP-C): subcellular localization and differential expression in relation to NSPA. European journal of cell biology. 1996; 69:197-213.

70. Melino S, Nepravishta R, Bellomaria A, Di Marco S, Paci M. Nucleic acid binding of the RTN1-C C-terminal region: toward the functional role of a reticulon protein. Biochemistry. 2009; 48:242-253.

71. Moser MA, Hagelkruys A, Seiser C. Transcription and beyond: the role of mammalian class I lysine deacetylases. Chromosoma. 2014; 123:67-78.

72. Wilson BJ, Tremblay AM, Deblois G, Sylvain-Drolet G, Giguere V. An acetylation switch modulates the transcriptional activity of estrogen-related receptor alpha. Molecular endocrinology (Baltimore, Md). 2010; 24:1349-1358.

73. Han G, Gupta SD, Gable K, Niranjanakumari S, Moitra P, Eichler F, Brown RH Jr, Harmon JM, Dunn TM. Identification of small subunits of mammalian serine palmitoyltransferase that confer distinct acyl-CoA substrate specificities. Proceedings of the National Academy of Sciences of the United States of America. 2009; 106:8186-8191.

74. Tidhar R, Futerman AH. The complexity of sphingolipid biosynthesis in the endoplasmic reticulum. Biochimica et biophysica acta. 2013; 1833:2511-2518.

75. Bhardwaj A, Singh S, Srivastava SK, Honkanen RE, Reed E, Singh AP. Modulation of protein phosphatase 2A activity alters androgen-independent growth of prostate cancer cells: therapeutic implications. Molecular cancer therapeutics. 2011; 10:720-731.

76. Harmon JM, Bacikova D, Gable K, Gupta SD, Han G, Sengupta N, Somashekarappa N, Dunn TM. Topological and functional characterization of the ssSPTs, small activating subunits of serine palmitoyltransferase. The Journal of biological chemistry. 2013; 288:10144-10153. 
77. Perry DK, Carton J, Shah AK, Meredith F, Uhlinger DJ, Hannun YA. Serine palmitoyltransferase regulates de novo ceramide generation during etoposide-induced apoptosis. The Journal of biological chemistry. 2000; 275:9078-9084.

78. Stipp CS, Kolesnikova TV, Hemler ME. EWI-2 is a major CD9 and CD81 partner and member of a novel Ig protein subfamily. The Journal of biological chemistry. 2001; 276:40545-40554.

79. Sala-Valdes M, Ursa A, Charrin S, Rubinstein E, Hemler ME, Sanchez-Madrid F, Yanez-Mo M. EWI-2 and EWI-F link the tetraspanin web to the actin cytoskeleton through their direct association with ezrin-radixin-moesin proteins. The Journal of biological chemistry. 2006; 281:19665-19675.

80. Hong IK, Kim YM, Jeoung DI, Kim KC, Lee H. Tetraspanin CD9 induces MMP-2 expression by activating p38 MAPK, JNK and c-Jun pathways in human melanoma cells. Experimental \& molecular medicine. 2005; 37:230-239.

81. Murayama Y, Miyagawa J, Oritani K, Yoshida H, Yamamoto K, Kishida O, Miyazaki T, Tsutsui S, Kiyohara T, Miyazaki Y, Higashiyama S, Matsuzawa Y, Shinomura Y. CD9-mediated activation of the p46 Shc isoform leads to apoptosis in cancer cells. Journal of cell science. 2004; 117:3379-3388.

82. Yi T, Kim HJ, Cho JY, Woo KM, Ryoo HM, Kim GS, Baek JH. Tetraspanin CD9 regulates osteoclastogenesis via regulation of p44/42 MAPK activity. Biochemical and biophysical research communications. 2006; 347:178-184.

83. Gioeli D, Black BE, Gordon V, Spencer A, Kesler CT, Eblen ST, Paschal BM, Weber MJ. Stress kinase signaling regulates androgen receptor phosphorylation, transcription, and localization. Molecular endocrinology (Baltimore, Md). 2006; 20:503-515.

84. Ueda T, Bruchovsky N, Sadar MD. Activation of the androgen receptor $\mathrm{N}$-terminal domain by interleukin-6 via MAPK and STAT3 signal transduction pathways. The Journal of biological chemistry. 2002; 277:7076-7085.

85. Ueda T, Mawji NR, Bruchovsky N, Sadar MD. Ligandindependent activation of the androgen receptor by interleukin- 6 and the role of steroid receptor coactivator- 1 in prostate cancer cells. The Journal of biological chemistry. 2002; 277:38087-38094.

86. Yan Y, Shirakabe K, Werb Z. The metalloprotease Kuzbanian (ADAM10) mediates the transactivation of EGF receptor by $\mathrm{G}$ protein-coupled receptors. The Journal of cell biology. 2002; 158:221-226.

87. Arima T, Enokida H, Kubo H, Kagara I, Matsuda R, Toki K, Nishimura H, Chiyomaru T, Tatarano S, Idesako T, Nishiyama K, Nakagawa M. Nuclear translocation of ADAM-10 contributes to the pathogenesis and progression of human prostate cancer. Cancer science. 2007; 98:1720-1726.

88. Rappa G, Green TM, Lorico A. The Nuclear Pool of Tetraspanin CD9 Contributes to Mitotic Processes in Human Breast Carcinoma. Molecular cancer research: MCR. 2014.
89. Hori H, Yano S, Koufuji K, Takeda J, Shirouzu K. CD9 expression in gastric cancer and its significance. The Journal of surgical research. 2004; 117:208-215.

90. Hemler ME. Tetraspanin proteins promote multiple cancer stages. Nature reviews Cancer. 2014; 14:49-60.

91. Chuan Y, Pang ST, Bergh A, Norstedt G, Pousette A. Androgens induce CD-9 in human prostate tissue. International journal of andrology. 2005; 28:291-296.

92. Pflueger D, Terry S, Sboner A, Habegger L, Esgueva R, Lin PC, Svensson MA, Kitabayashi N, Moss BJ, MacDonald TY, Cao X, Barrette T, Tewari AK, Chee MS, Chinnaiyan AM, Rickman DS, et al. Discovery of nonETS gene fusions in human prostate cancer using nextgeneration RNA sequencing. Genome research. 2011; 21:56-67.

93. Charrin S, Le Naour F, Labas V, Billard M, Le Caer JP, Emile JF, Petit MA, Boucheix C, Rubinstein E. EWI-2 is a new component of the tetraspanin web in hepatocytes and lymphoid cells. The Biochemical journal. 2003; 373:409-421.

94. Zhang XA, Lane WS, Charrin S, Rubinstein E, Liu L. EWI2/PGRL associates with the metastasis suppressor KAI1/CD82 and inhibits the migration of prostate cancer cells. Cancer research. 2003; 63:2665-2674.

95. Kolesnikova TV, Kazarov AR, Lemieux ME, Lafleur MA, Kesari S, Kung AL, Hemler ME. Glioblastoma inhibition by cell surface immunoglobulin protein EWI-2, in vitro and in vivo. Neoplasia. 2009; 11:77-86. 74p following 86.

96. Kawashima M, Doh-ura K, Mekada E, Fukui M, Iwaki T. CD9 expression in solid non-neuroepithelial tumors and infiltrative astrocytic tumors. The journal of histochemistry and cytochemistry: official journal of the Histochemistry Society. 2002; 50:1195-1203.

97. Shtutman M, Baig M, Levina E, Hurteau G, Lim CU, Broude E, Nikiforov M, Harkins TT, Carmack CS, Ding Y, Wieland F, Buttyan R, Roninson IB. Tumor-specific silencing of COPZ2 gene encoding coatomer protein complex subunit zeta 2 renders tumor cells dependent on its paralogous gene COPZ1. ProcNatlAcadSciUSA. 2011; 108:12449-12454.

98. Vancha AR, Govindaraju S, Parsa KV, Jasti M, GonzalezGarcia M, Ballestero RP. Use of polyethyleneimine polymer in cell culture as attachment factor and lipofection enhancer. BMCBiotechnol. 2004; 4:23.

99. Chen M, Tanner M, Levine AC, Levina E, Ohouo P, Buttyan R. Androgenic regulation of hedgehog signaling pathway components in prostate cancer cells. Cell cycle (Georgetown, Tex). 2009; 8:149-157.

100. Fontes R, Dukhovich A, Sillero A, Sillero MA. Synthesis of dehydroluciferin by firefly luciferase: effect of dehydroluciferin, coenzyme A and nucleoside triphosphates on the luminescent reaction. Biochemical and biophysical research communications. 1997; 237:445-450. 